\title{
Más allá de la metrópoli. La difusión espacial de la residencia de los grupos sociales con ingresos medios y altos de Bogotá
}

\author{
Beyond the metropolis. The spatial diffusion of the residence \\ of middle- and high-income social groups in Bogotá
}

Melba Rubiano Bríñez

\begin{abstract}
Resumen
Los cambios en la composición social en el mundo inciden en la forma de apropiación del territorio. A diferencia de otros enfoques convencionales del análisis del crecimiento urbano y de las jerarquías de ciudades, parte del crecimiento poblacional y físico se manifiesta en zonas relativamente alejadas del hinterland metropolitano, involucrando a familias de ingresos medios y altos diferenciadas por su ciclo de vida productivo. El objetivo del artículo es analizar el impacto en el crecimiento físico--poblacional de las migraciones estructurales -cambios de residencia principal - de residentes en Bogotá. La difusión espacial en el espacio pos-metropolitano confirma la formación de convenciones urbanas y repite los patrones de segregación socio espacial con impacto en la segmentación del mercado inmobiliario de los municipios observados.
\end{abstract}

Palabras clave: metropolización, autosegregación, Bogotá, mercado del suelo, topopoligamia.

\begin{abstract}
Changes in social composition across the world affect the form of appropriation of the territory. Unlike other conventional approaches to the analysis of urban growth and cities' hierarchies, part of the physical and population growth manifests itself in areas relatively distant from the metropolitan influence area, involving middleand high-income families differentiated by their productive life cycle. The aim of this paper is to analyze the impact, on physical and population growth, of the structural migrations - changes of principal household - of Bogotá residents. Spatial diffusion in the post-metropolitan area confirms the development of urban conventions and repeats patterns of socio-spatial segregation with an impact on the segmentation of the real estate market of the municipalities observed in the study.
\end{abstract}

Keywords: metropolization; self-segregation; Bogotá; land market; topopoligamia. 


\section{Introducción ${ }^{1}$}

Para hacer una aproximación al análisis sobre el proceso de difusión residencial de los grupos sociales con ingresos medios y altos de Bogotá en el espacio posmetropolitano de influencia de la metrópoli, a fin de entender cómo la dinámica socio espacial reciente encarna nuevas interacciones espaciales motivadas por decisiones de auto segregación, esta investigación evidencia la necesidad de reorientar los esfuerzos de la política pública urbana hacia un horizonte más lejano del ámbito metropolitano.

Un estudio reciente (Alfonso, 2015) describe tal horizonte indicando nuevos derroteros para el análisis de las implicaciones territoriales en un ámbito totalmente nuevo: el posmetropolitano. Esta nueva escala de análisis sirve de marco para estudiar y comprender las dinámicas territoriales y espaciales que se verifican por la irrupción de condominios y construcción residencial dispersa en jurisdicciones relativamente alejadas de la zona metropolitana pero dotadas de ciertos atractivos paisajísticos y ambientales como son los casos de Ricaurte en el Departamento de Cundinamarca y Villa de Leyva en el Departamento de Boyacá.

La dinámica de estos fenómenos urbanos tiene implicaciones sobre los municipios de tal manera que emergen externalidades negativas ambientales y en materia de movilidad, motivadas en los estilos de vida de los nuevos residentes cuyos hábitos y costumbres se implantan en los lugares receptores. Tal como es estudiado desde el punto de vista sociológico
(Augé, 2007), la movilidad pendular por la que deambulan, indica que esos hogares ya no pertenecen a un solo lugar y se refuerza con la visión del surgimiento de la topopoligamia como característica de personas con altos ingresos que pertenecen a varios lugares y no pertenecen a ninguno (Beck, 2008).

Acorde con las investigaciones sobre movilidad de Augé (2007), este proceso es también la territorialización de las relaciones de poder de las capas sociales adineradas. Haesbaert (2014) estudia ese tipo de relaciones y propone la transterritorialidad como noción para abordar el estudio del territorio como uno de los dominios del espacio geográfico, desde una constelación de conceptos geográficos en donde también se cuenta el paisaje, el lugar y el ambiente. Así, no solamente se estudia la pos-metropolización como fenómeno reciente sino las condiciones que promueven formas de auto segregación y, además, la dinámica del mercado inmobiliario en estos municipios.

La primera parte recoge los principales aspectos metodológicos de soporte del estudio, para luego discutir las nociones de pos-metropolitanismo y transterritorialidad, con los que se adelanta el análisis de los dos casos mencionados, Villa de Leyva y Ricaurte.

\section{Aproximación metodológica al estudio del ámbito posmetropolitano}

Las dimensiones de análisis y principales elementos conceptuales se identificaron a partir de la revisión de un trabajo reciente 
de Alfonso (2015), quien elaboró el Índice Alternativo de Desarrollo Municipal (IADM), pues es una propuesta novedosa para analizar los desequilibrios en la ocupación del territorio, siendo uno de sus resultados más relevantes la identificación de Ricaurte y Villa de Leyva como las jurisdicciones municipales en las que se refleja el crecimiento urbano de la metrópoli bogotana más allá de su área de influencia inmediata, la Sabana de Bogotá. Este estudio suscitó la siguiente cuestión: ¿Qué impactos territoriales ha originado el establecimiento de las residencias principales y secundarias de familias bogotanas de ingresos medios o altos en esos municipios de escala pos-metropolitana, Ricaurte o Villa de Leyva?

Aparte de la revisión de la literatura pertinente se recopiló información sobre los dos municipios de referencia utilizando diferentes instrumentos, entre ellos: una encuesta aplicada a los residentes de los proyectos inmobiliarios para captar información primaria sobre las razones que los llevaron a tomar de decisión de trasladar su lugar de residencia a estos municipios, adicionalmente, se recurrió a la observación directa en campo y a la revisión documental en las entidades más significativas a nivel local como es el caso de la Secretaría de Planeación y se hicieron entrevistas en profundidad con algunos actores claves para la investigación. A partir de la información recopilada se identificaron factores similares y singularidades del fenómeno estudiado en cada ente territorial.

\section{El ámbito posmetropolitano como marco de análisis}

Se aduce que es evidente un desarrollo de las ciudades que indican una tendencia a la metropolización con presencia de conurbaciones, entendidas como prolongaciones del núcleo principal hacia la ciudad más próxima y con gran influencia sobre la misma por condiciones de movilidad cotidiana y laboral. En este sentido, la metropolización de Bogotá y su área de influencia como señalan Rentería y Umaña (2011), indican que la tendencia de la espacialización en Colombia ha seguido el modelo de primacía urbana como resultado de la concentración de población y actividades que giran en torno de una gran ciudad, como es el caso de Bogotá y los 116 municipios del Departamento de Cundinamarca, los cuales conforman en su conjunto a la Región Capital (Alcaldía Mayor de Bogotá, 2010). En este sentido, se reconoce que Cundinamarca es uno de los departamentos más relevantes en términos de productividad, competencia y desarrollo económico.

Por otra parte, Alfonso (2001, p. 22), señala que si bien la región metropolitana conformada por Bogotá y los municipios de la Sabana, no están constituidas legalmente como una unidad político-administrativa definida, presentan una interacción de sus principales mercados, comparten un espacio geográfico y se consolidan en la cúspide de la red colombiana de ciudades, señalando la 
espontaneidad de un proceso colectivo de construcción territorial sobre la cual gravita la dinámica socioeconómica y política del país. La interacción a la cual se refiere Alfonso se ha intensificado en las últimas décadas y se relaciona, como ya se mencionaba antes, con los movimientos cotidianos.

Los desequilibrios territoriales presentes en las áreas metropolitanas analizados en la literatura revisada, ponen de manifiesto la necesidad de abordar el estudio de las implicaciones relacionadas con la metropolización para entender que, si bien desde hace muchos años se habla de los impactos del crecimiento urbano acelerado, hasta hace poco la gestión urbana podía ser manejada desde lo municipal. Hoy en día, lo que se denomina como lo urbano ya no corresponde solamente con los límites de las jurisdicciones locales, lo que implica que es necesario idear mecanismos para gestionar asuntos metropolitanos como servicios públicos, servicios ambientales, vivienda y transporte, entre otros.

Además, se advierte la ampliación del umbral del ámbito metropolitano hacia municipios que han sido considerados tradicionalmente como fuera del área de influencia de Bogotá. En la revisión de la literatura se vislumbra que el crecimiento espacial y demográfico y las interacciones que se dan entre un núcleo principal y uno o varios municipios metropolizados que son entendidos como procesos de metropolización, generan impactos en la composición social del espacio, generando formas de exclusión, segregación y hasta autosegregación. De tal manera, que lo que antes se consideraban como periferias pasan a ser lugares centrales y la población más pobre termina desplazada a nuevas fronteras y periferias con graves deficiencias de localización e infraestructura, lo que redunda en el agravamiento del deterioro de su calidad de vida.

El planteamiento teórico lleva a la proposición de variables para establecer lo que el autor ha denominado como Índice Alternativo de Desarrollo Municipal (IADM). Es alternativo porque, primero, no se basa en variables censales $y$, segundo, por el soporte teórico sobre los conceptos de "fragilidad y resistencia territoriales". En suma, lo que señala Alfonso es que la fragilidad geográfica se verifica en la sinuosidad y las distancias entre ciudades que tiene implicaciones sobre el incremento en costos de transporte, lo que, en últimas redunda en pérdida de competitividad. De tal manera, que el análisis planteado por el autor muestra cómo existe una fragilidad en el sistema vial dado que algunas ciudades no están conectadas en modo alguno con Bogotá.

Señala Alfonso, cuando hay una mejor distribución del ingreso personal y de la riqueza coincide con el hecho que la democracia funciona mejor y la elevación de las condiciones de vida es persistente. En contraposición, se observa que cuando hay concentración de la propiedad territorial es "sintomática de un estadio de subdesarrollo pues entraña, en no pocos casos, la reproducción generacional de la desigualdad de oportunidades para explotar la tierra, la apropiación indebida de derechos de propiedad, inclusive con el uso de la violencia, y la inmovilización territorial para la producción especialmente en el caso de la propiedad latifundiaria" (Alfonso, 2015, p. 42). 
Se hace énfasis en que, tal como señala el autor, la falta de equidad en la distribución de la propiedad territorial es un elemento desestabilizador de los equilibrios territoriales y que tiene consecuencias, además, sobre otros aspectos, como la seguridad alimentaria y conflictos de poder generados por la disputa por la propiedad de la tierra, siendo éste un factor detonador de la violencia que ha padecido Colombia desde hace décadas.

En línea con este análisis, señala Alfonso que la inequidad en la distribución de la tierra implica problemas de exclusión de la población y con miras a dar solución a esta problemática, el Estado trata de intervenir a través del gasto público local lo cual, sin embargo, si se mira a partir de la provisión de bienes públicos también se observan desequilibrios entre los municipios, siendo que algunas ciudades disponen de más recursos que otras, provocando una migración de la población hacia esas "grandes ciudades" lo que enfatiza los desequilibrios en la distribución de la población sobre el territorio.

Lo que resulta relevante para la investigación de la difusión espacial de la residencia de los grupos sociales con ingresos medios y altos en ámbitos pos-metropolitanos, lo constituye la constatación de la influencia de las dos principales ciudades del país, Bogotá y Medellín, sobre los municipios en su entorno y aún más allá de lo que, geográficamente se considere cercano a estos municipios. Esto último, se constata cuando, de acuerdo al IADM se verifica la influencia de Bogotá con Villa de Leyva que ha sido considerada fuera de ese umbral de influjo bogotano. En este sentido, un rasgo identificado por Alfonso y que resulta coherente con el análisis que se busca hacer sobre los ámbitos posmetropolitanos se relaciona con la identificación de una fragmentación territorial que tiene implicaciones conforme la "intervención selectiva" del Estado. En este caso, se identifica con los diferentes niveles de relación con municipios que, se ubican más cerca o más lejos del núcleo principal metropolitano. De ahí, identifica nueve zonas metropolitanas que poseen diferentes grados de IADM lo que refuerza la idea de la heterogeneidad territorial y espacial, también, conforme ha identificado las categorías de análisis territorial, señala las diferencias en los índices que han sido calculados (capitales no metropolizadas, núcleos principales, municipios de crecimiento estable). "Estos últimos tres regímenes presentan una considerable heterogeneidad espacial al decir de la considerable amplitud de los rangos del IADM (Alfonso, 2015, p. 54).

Para los propósitos de la investigación realizada resultó pertinente hacer uso de la categoría analítica espacial que se identifica con lo que denomina el autor como "municipios de crecimiento estable" y que poseen valores del IADM elevados. En este sentido, identifica tres ejes que dan muestra del desequilibrio en la ocupación territorial y que surge a partir de la influencia posmetropolitana de Bogotá hacia municipios como Ricaurte en Cundinamarca y Villa de Leyva en Boyacá, y un eje diferente a partir de la influencia metropolitana de Medellín.

El estudio de Alfonso (2015) señala que en los municipios de Ricaurte (Cundinamarca) y Villa de Leyva (Boyacá) se ha establecido un grupo poblacional de ingresos mediosaltos y altos de la Capital que se autosegrega estableciendo en un primer momento, la 
segunda residencia y que posteriormente, se convierte en primera residencia. En términos generales, lo que muestra el ejercicio realizado son las divergencias en términos de desarrollo local desde la perspectiva territorial discutida y que genera mutaciones en el ordenamiento territorial, de tal manera que, se identifica que el núcleo metropolitano ejerce una influencia sobre la zona de influencia cuyo impacto se verifica si se observa que la difusión hacia los suburbios residenciales, ya no solamente inmediatos sino más alejados (posmetropolitanos).

En síntesis, lo que se ha identificado hasta aquí es que, una vez calculado el IADM, Ricaurte y Villa de Leyva presentan un índice más alto que el promedio de los municipios metropolizados en la zona de influencia de la zona pos-metropolitana Bogotá. Se hace énfasis en que Alfonso asume el municipio como la unidad de observación, lo que coincide con el trabajo aquí propuesto, a pesar de tratarse de la relación entre los municipios pero que se estudian a la luz de los ámbitos posmetropolitanos.

En el espacio que queda entre Bogotá y estos municipios se localizan zonas de menor atractivo para el desarrollo inmobiliario u otras actividades productivas que confirman la selectividad cuyo resultado es la fragmentación territorial. Como señala Alfonso, la fragmentación se genera por la intervención del Estado, en otras palabras, la intervención selectiva del Estado genera la fragmentación territorial. Existe fragmentación territorial porque el desarrollo no es homogéneo, tal como lo evidencia los diferentes datos del
IADM. Existen territorios con un desarrollo claramente diferenciado.

Para Alfonso (2015) la fragmentación es analizada desde el punto de vista de las relaciones de poder, para Haesbaert la fragmentación desde el punto de vista geográfico; sin embargo, ambos estudian las relaciones de poder sobre el espacio geográfico. En el caso de Haesbaert, asume que el territorio se estudia desde el punto de vista del poder, tanto en el sentido económico como simbólico.

A diferencia de Soja que entiende la postmetropolis como la ciudad después de la modernidad como la última etapa de la geohistoria del espacio urbano, Alfonso (2015) lo asume como el espacio geográfico que va más allá del ámbito de influencia de la zona metropolitana. Soja lo plantea como la transición entre lo que permanece y lo que cambia, como un nuevo urbanismo que representa la transformación de las ciudades. Este nuevo urbanismo, como señala Ascher (2010) se evidencia en la metapolización como "un nuevo proceso de metropolización y de formación de nuevos tipos de territorios" (Ascher, 2010, p. 62) y también se verifica en las vastas conurbaciones que se presentan a lo largo de la zona estudiada con presencia de algunos espacios discontinuos y con amplia heterogeneidad en las características de su espacio geográfico.

Este marco teórico se justifica para el tema porque explica cómo se determinan los municipios que fueron seleccionados y el de Haesbaert para mirar el tema de la desterritorialización que se asume como 
una reterritorialización porque el territorio se destruye y construye de nuevo. Además, que ambos autores se refieren al poder como dimensión a tener en cuenta en el análisis realizado, aunque cada uno con una diferente particularidad sobre el mismo. Para Haesbaert lo analiza desde el punto de vista de las relaciones económicas y simbólicas. Para Alfonso, es notable el interés por mirar el poder del Estado y su impacto en la generación de desequilibrios territoriales y como fragmentador del territorio.

De acuerdo con Haesbaert la gente se desplaza a otro territorio y lo ocupa de tal manera, que lo interviene y hace una reterritorialización o multiterritorialización. De otro lado, de acuerdo con lo que plantea Alfonso, existen unas fragilidades y resistencias territoriales que, según la metodología planteada, calcula un índice alternativo de desarrollo municipal con lo que ubica los municipios en una determinada escala, en razón a esta escala se determina los municipios estudiados.

En este caso: "El IADM es un instrumento de utilidad para verificar tanto los desequilibrios en la ocupación del territorio, como para captar la manera como la intervención selectiva del Estado ocasiona una fragmentación territorial que es aupada por las dinámicas capitalistas contemporáneas" (Alfonso, 2015, p. 59). Esta es la razón por la que se justifica su pertinencia para el marco teórico, para explicar los desequilibrios territoriales y la fragmentación territorial.

Es de resaltar que el crecimiento de Bogotá se aceleró a partir de mitad del siglo $X X$. En la Figura 1 se presentan algunos cortes temporales que muestran la expansión física de la ciudad, a través del crecimiento de su perímetro urbano. Según la imagen se observa que entre 1950 y 2000 Bogotá se extendió hacia el norte, pero espacialmente hacia el occidente. Fue durante este período, específicamente en 1953, cuando se anexaron cinco municipios a saber: Bosa, Usme, Fontibón, Engativá y Usaquén.

Debido a la anexión de estos municipios pertenecientes al departamento de Cundinamarca que, de hecho, fue realizada de manera autoritaria durante un período dictatorial, desde entonces se ha erigido un discurso anti-bogotano en la Sabana de Bogotá centrado en la denuncia del interés de la capital de absorber más municipios para facilitar su ensanchamiento, no obstante que la Constitución Política de 1991 establece reglas muy exigentes para que ello pueda ocurrir. 
Figura 1 - Expansión urbana de Bogotá

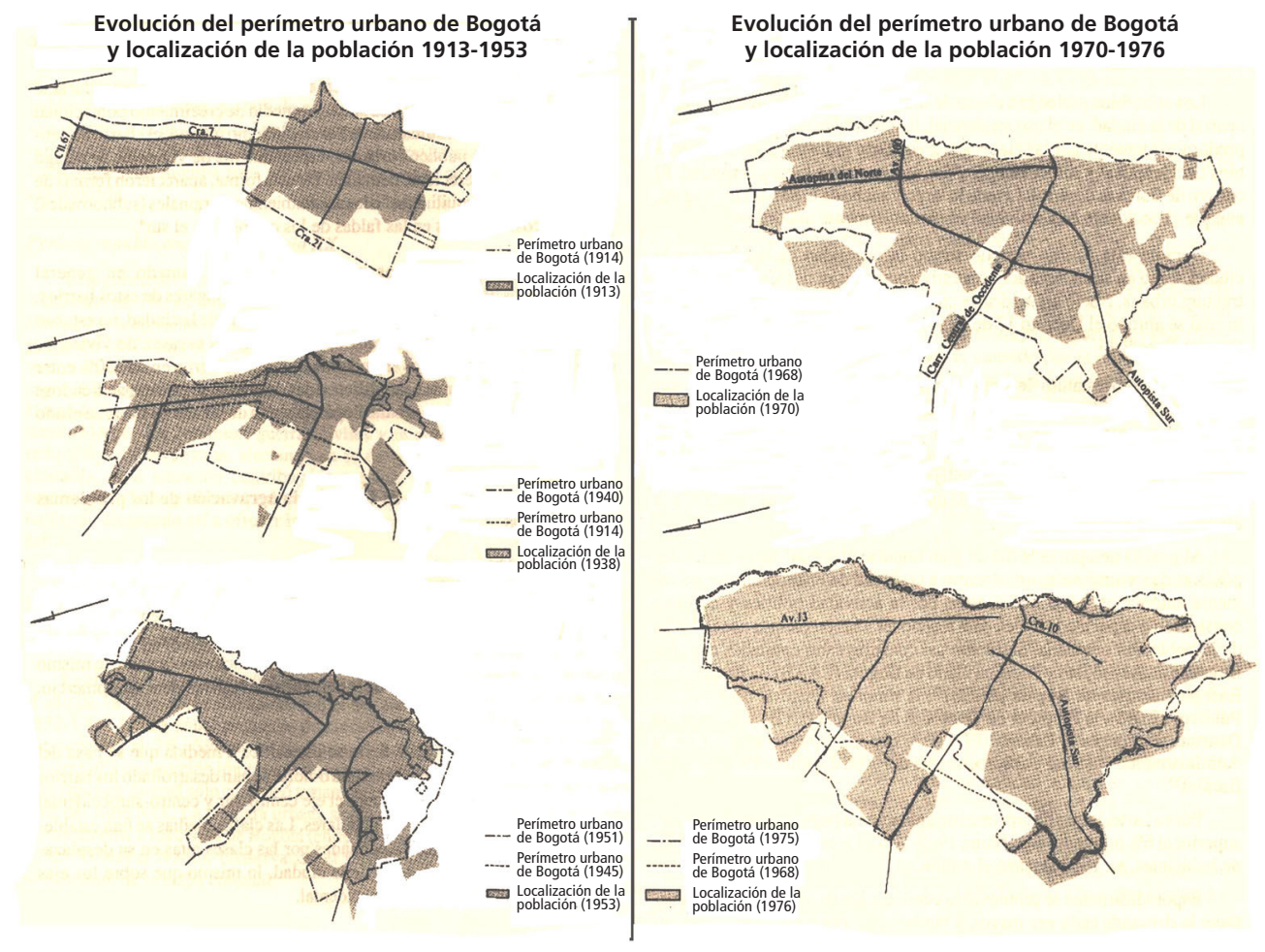

Fuente: Losada Lora (1976), citado en Hataya et al. (1994, pp. 18-19).

\section{De lo territorial a la multiterritorialidad: una constelación de conceptos geográficos}

Haesbaert (2014), analiza el territorio ligado al concepto de poder como control de procesos sociales mediante el control del espacio. Para ello recurre a autores como Focault, entre otros, haciendo un análisis desde el punto de vista de las relaciones de poder de los grupos que denomina como hegemónicos, lo que implica para otros grupos, la pérdida de control territorial. Asume, la desterritorialización que implica una destrucción y reconstrucción territorial. En este caso, se puede argumentar que el mercado inmobiliario induce la movilidad, por traslado de territorio en cuyo caso la construcción simbólica, a partir de la reterritorizalización, es decir, como una especie de "destrucción creativa", en términos schumpeterianos, permite crear y recrear el territorio, en otras palabras, destruir para levantar de nuevo. Transformarlo y asumirlo 
desde la percepción simbólica del mismo, lo cual podría ser medido desde el enfoque de la satisfacción residencial.

Para Haesbaert, el territorio incluye también la dimensión de la movilidad, de la acción, por eso habla de dinámicas de desterritorialización antes que de territorios estables. Asegura que el territorio debe ser concebido como producto del movimiento combinado de desterritorialización y de reterritorialización, es decir, de las relaciones de poder construidas en y con el espacio, considerando el espacio como un constituyente, y no como algo que se pueda separar de las relaciones sociales.

Señala que autores, como Milton Santos, intentaron superar la dicotomía espacio/tiempo. Santos, por ejemplo, tiene una concepción muy amplia del territorio, que aparece muchas veces como sinónimo de espacio. Dice que el territorio es un conjunto de sistemas de objetos y sistemas de acciones, tanto de acciones como de objetos. Haesbaert destaca esto, porque entiende el espacio no como algo estático, sino como algo abierto para ser reconstruido. En este sentido, la dimensión espacial geográfica no es estable, está en constante movimiento dado que los sistemas urbanos de las metrópolis se van desarrollando y generando cambios como conurbaciones, cambios de lo rural a lo urbano, por ejemplo. No obstante, que los municipios tienden a conservar y promover los vínculos con el núcleo central dadas las relaciones cotidianas y el crecimiento mismo de la aglomeración urbana, lo que Soja (2008) ha denominado sinecismo, entendido como la tendencia hacia la aglomeración.

Para el análisis planteado, parte de la discusión entre lo móvil e inmóvil; entre lo funcional y lo simbólico, toda vez, que asume que el territorio no es una dimensión estática, sino que está en movimiento. En este sentido, Haesbaert propone la construcción de territorios a partir de la movilidad, a partir de establecer que se produce un doble movimiento, reterritorializador y desterritorializador, según la movilidad se produzca bajo condiciones controladas, como, por ejemplo, grupos de población pobres que pasan mucho tiempo movilizándose de un lugar a otro. Pero, también, cuando grupos con altos ingresos tienen pleno control de los lugares en los cuales se mueven a voluntad. El sentido desterritorializador lo analiza a partir de la movilidad que implica precarización de las condiciones de calidad de vida.

Cabe anotar, que en términos de la investigación propuesta, se estudia el caso en que los pobladores que se autosegregan lo hacen porque deciden hacerlo, es decir, corresponde a un grupo de población que cuenta con recursos económicos para hacerlo, no son desplazados por la violencia, ni se trata de población que se ve movilizada por otras causas diferentes a la búsqueda de condiciones que les garanticen una mejor calidad de vida u otras razones que son objeto de análisis en el desarrollo de esta investigación.

En términos de lo que menciona Haesbaert, se refiere a la situación en la que los grupos hegemónicos se movilizan, no es una "desterritorialización" porque tienen control de su movilidad (se movilizan porque quieren o deciden hacerlo), en los grupos precarios, si lo es porque se están desplazando y perdiendo calidad de vida, como en el caso de los desplazados por la violencia. 
Dice Haesbaert que en este caso sí se puede hablar de una movilidad intensificada que desterritorializa; por lo tanto, según el autor, la desterritorialización es un término muy equivocado cuando se aplica a las condiciones en las que los grupos hegemónicos se movilizan y que se lleva a cabo, completamente "bajo control". Señala, además, que a la luz de lo que se está denominando como cultura globalizada, se habla en términos de movilidad y multiplicidad de donde emerge en su "constelación de conceptos" (Haesbaert, 2014, p. 34) la idea de "vivir en el límite", en el sentido que se vive en un mundo que mezcla identidades cuando se traspasan los límites de un territorio o espacio y que se asume una identidad que pasa de un lado a otro.

En este sentido, se puede decir que, de acuerdo con Haesbaert, se produce una reterritorialización cuando la movilidad está bajo control, lo que ocurre en las grandes empresas, pero también en los movimientos cotidianos de grupos subalternos (que pasan muchas horas desplazándose). Esa reterritorialización es muy evidente cuando se trata de los grupos más privilegiados, que pueden tener plenos poderes sobre sus circuitos de circulación.

Las condiciones en que se presenta la movilidad conllevan a reflexionar sobre la sensación de arraigo que puedan sentir algunas personas sobre el territorio sobre el cual se asientan pero también cuestionan sobre las características de esa población en cuanto a sus condiciones económicas (nivel de ingresos), franja etaria a la cual pertenecen, toda vez que, se ha asumido que algunos segmentos de la población de ingresos medios y altos que se clasifican como adultos mayores, es decir, pensionados, corresponden al grupo que se ubica en localizaciones periféricas y posmetropolitanas.

Cuando habla de región, hace referencia a que no es una cuestión que sea homogénea, sino que presenta diferencias y desigualdades, por lo que asumen como cuestión central en el estudio del concepto de región, pero en relación al poder. Por tanto, identificando que su tema de interés es "la multiplicidad contemporánea de tiempo - espacios, movilidades y fijaciones, aperturas y cerramientos de territorios, que refuerzan prácticas ligadas a la percepción de inseguridad e incertidumbre, una especie de vida en el límite o en la frontera" (Haesbaert, 2014 , p. 14), se colige que el autor señala una movilidad espacial que le permite trasladarse de un espacio a otro, donde asume una identidad que desde el campo de los simbólico, se mueve entre uno y otro espacio, de tal manera que puede hacer lo que denomina como "reterritorialización" en el sentido, de que el individuo puede reconstruir el espacio que habita, pero que todo esto, se da dentro de un panorama de incertidumbre que genera conflictos, como la búsqueda por el control del territorio y que induce a las diferentes formas de intervención del estado, que genera desequilibrios territoriales.

En el marco de la revisión de la literatura y de establecer el estado del arte sobre el estudio del tema que concierne a la investigación, a continuación de presentar el abordaje que tanto Haesbaert como Alfonso presentan, se tomaron las dimensiones claves que aportan para la construcción teórica, y a partir de ahí se propuso un punto de encuentro para articular los enfoques. Sin embargo, 
con fundamento en el marco de análisis identificado surgen nuevos cuestionamientos que aportan al estudio de la difusión espacial en ámbitos posmetropolitanos.

¿Cuál es el papel desterritorializador del Estado? En este aspecto, Alfonso se refiere al papel del Estado que produce fragmentaciones en el territorio, dados sus diferencias en la escala de intervención.

De otro lado, Haesbaert habla del papel desterritorializador del Estado, de donde surge la cuestión de ¿cómo y por qué desterritorializa?

Así mismo, Alfonso, hace referencia al papel del Estado como agente fragmentador, pero ¿cómo y por qué el Estado fragmenta?

Al respecto, por un lado, Alfonso habla del IADM que permite categorizar los municipios para determinar las relaciones de posmetropolización con Bogotá y de ahí sale la selección de Ricaurte y de Villa de Leyva. Por el lado de Haesbaert, se aborda por la manera como estudia la territorialización que ejerce control y construye un territorio, de tal manera que lo reconstruye, lo modifica.

A partir del IADM se seleccionan los municipios que fueron objeto de análisis, y a partir de los aportes teóricos de Haesbaert y Alfonso, se estudian cómo se produce esa apropiación de los nuevos residentes que se autosegregan de tal manera que se desplazan a un nuevo territorio y se verifican unas relaciones de poder, que dada las condiciones económicas de quienes se desplazan, se trata de un dominio de tipo económico donde ellos aprovechan las condiciones del mercado inmobiliario para adquirir vivienda y condiciones que les garantizan un mejoramiento en su calidad de vida.
Los desequilibrios territoriales son analizados desde el punto de vista de las diferencias en cuanto al desarrollo municipal (dado por el IADM) y también por el Ilamado papel desterritorializador del Estado (Haesbaert, 2014) y de fragmentación territorial (Alfonso, 2015).

De acuerdo con el argumento de Haesbaert, cuando se refiere a la precarización asume la "desterritorialización como destrucción y abandono de un territorio y también, como precarización territorial por grupos subalternos". Asume la desterritorialización como precarización de procesos sociales, que en caso contrario se refiere a la territorizalización cuando se trata del traslado de grupos con poder económico que asume el control de un territorio, de tal manera que se apropia de él. Un aspecto relevante para el análisis es que Haesbaert analiza, desde el punto de vista foucaltiano, el poder disciplinario y el poder soberano haciendo referencia al poder disciplinario que implica disciplinas como la estadística como "ciencia del Estado" y que busca controlar la población, lo que se contrapone a la posición de Alfonso que basa el análisis y las variables que identifica sin necesidad de recurrir a los datos censales dado que la información disponible data de 2005.

En coherencia con las relaciones de poder a las cuales se refieren tanto Alfonso como Haesbaert, se vincula otro enfoque que ofrece un concepto que se incluye dentro de la constelación de conceptos y que no es nuevo, pero ha sido poco estudiado; la topopoligamia. Término que de acuerdo con Beck (2008) indica un nuevo derrotero para el análisis de las implicaciones que la globalización ha 
generado, no solamente sobre las relaciones económicas sino las sociales y el modo de vida urbano. En sentido estricto, la topopoligamia es la posibilidad de "estar alguien casado con varios lugares y pertenecer a varios mundos" (Beck, 2008, p. 148), que se equipara con la visión de vivir en el límite de Haesbaert en el sentido de que, actualmente, dado el modo de vida que se desarrolla dentro de un contexto capitalista, es posible moverse entre espacios geográficos diferentes pasando de un territorio a otro.

El hecho de que el modo de vida urbano brinda la posibilidad de que, actualmente, ya no signifique estar atado a un solo lugar, ya no siempre se tiene un ciclo de vida asentado y sedentario (Beck, 2008, p. 149), sino que la topopoligamia, posibilita la búsqueda que se adapte y se apropie del estilo de vida en uno u otro territorio, con una movilidad sobremoderna que como argumenta Augé (2007) permite que el hombre sea capaz de ocupar todo el planeta sin restricciones, tanto en un sentido virtual como físico y convivir en diferentes espacios.

Lo que se señala aquí es que la globalización y el modo de vida capitalista permiten que las personas con dinero se muevan dentro de diferentes territorios y eso les permite que sea posible pasar de una identidad territorial a otra. Esa movilidad que examina Augé (2007), cuando estudia la antropología de la movilidad y que se identifica con la desterritoralización y territorialización que también ha sido estudiada por Haesbaert. Este es el abordaje teórico que enmarcó la investigación y, por lo tanto, esta reflexión.

\section{La difusión espacial posmetropolitana de la residencia de los hogares con ingresos altos y medios de Bogotá}

Con el abordaje teórico y la investigación desarrollada se buscó abordar la segregación desde un punto de vista diferente, para lo cual se propuso revisar el fenómeno desde los actores que deciden autosegregarse para estudiar las condiciones en las cuales se lleva a cabo este proceso. Si bien se ha estudiado mucho en los últimos años el fenómeno de metropolización en el contexto latinoamericano, conurbaciones, etc., se sabe poco de estudios "regionales" y del impacto que tienen estas metrópolis sobre municipios más alejados que, sin embargo, se están transformando por acciones y decisiones descentralizadas de los actores y están generando nuevas relaciones/configuraciones territoriales. Se planteó analizar este fenómeno desde las estrategias residenciales de la población bogotana hacia los municipios seleccionados con base en el ciclo de vida y estructura de los hogares.

\section{Caracterización de la escala posmetropolitana de Bogotá}

El municipio de Ricaurte se encuentra ubicado a 142 kilómetros de Bogotá, cuenta con una extensión de $130 \mathrm{~km}^{2}$, con una temperatura media entre $27^{\circ}$ y $30^{\circ}$ centígrados y una 
altitud de 284 m.s.n., lo que hace un sitio agradable para los que buscan un clima cálido y seco. Según cifras oficiales (Instituto Geográfico Agustín Codazzi - IGAC) cuenta con 11.754 predios de los cuales 6.049 son urbanos. Según los datos del censo 2005, el municipio tenía 7.990 habitantes, con una densidad de 66.5 habitantes por kilómetro (hab/Km²), de los cuales el $60,8 \%$ nació en otro municipio. De acuerdo con el Dane Departamento Administrativo Nacional de Estadísticas, la población indica la siguiente dinámica: población proyectada para 2012 de 9.044 habitantes; para 2013 se prevé una población de 9.169 y para 2014, se considera una proyección poblacional de 9.314 habitantes en el municipio, con unas tasas de crecimiento de $1,38 \%$ y 1,58\% para 2013 y 2014, respectivamente. Sin embargo, la dinámica poblacional del municipio muestra el comportamiento censal de los últimos 3 períodos, manifestando una tendencia al crecimiento moderado en el período intercensal 1985 y 1993 y una tendencia más dinámica entre 1993 y 2005.

En el extremo opuesto, el municipio de Villa de Leyva se encuentra ubicado a 165 kilómetros de Bogotá y a 37 km de Tunja, capital del departamento de Boyacá. Cuenta con una extensión de $128 \mathrm{~km}^{2}$, con una temperatura media de $18,1^{\circ}$ centígrados y una altitud de 2.149 m.s.n. Cuenta con 7.531 predios distribuido así: 5.127 rurales y 2.444 urbanos (Hospital San Francisco, 2013, p. 14). En la zona urbana cuenta con 1.848 viviendas y 1.385, en la zona rural (www.sui. gov.co). De acuerdo con el censo 2005, el municipio tenía 9.645 habitantes, con unas proyecciones de población para 2012 de 15.027 habitantes; para 2013 de 15.502 y para 2014 de 15.983 habitantes, con unas tasas de crecimiento de 3,16\% y 3,1\% para 2013 y 2014, respectivamente. Con una densidad de 109,6 habitantes por kilómetro $\left(\mathrm{hab} / \mathrm{km}^{2}\right)$. Del total de habitantes reportados por el Dane en el censo 2005, el 35,14\% nació en otro municipio de Colombia, en tanto que el 0,33\% nació en otro país (Figura 2).

Las licencias de construcción residencial otorgadas en Ricaurte, indican un comportamiento con una marcada tendencia creciente de las mismas, especialmente, en los últimos años que se verifica desde 2010 hasta el 2013, que corresponde a los datos disponibles y suministrados por la Secretaría de Planeación Municipal, lamentablemente las cifras no estaban actualizadas cuando se hizo la consulta (Figura 3).

La información sobre las licencias de construcción, se recopiló a partir de la información suministrada en la Secretaría de Planeación Municipal de Villa de Leyva y se organizó tomando en cuenta la distribución de licencias para vivienda nueva por años. De acuerdo a la información obtenida, las licencias de construcción, presentan un comportamiento muy estable, toda vez que no se registran grandes movimientos en la tendencia, por lo menos en lo que atañe al período analizado entre 2010 y hasta 2014 (Figura 4). 
Figura 2 - Localización de los municipios objeto de análisis en relación a Bogotá

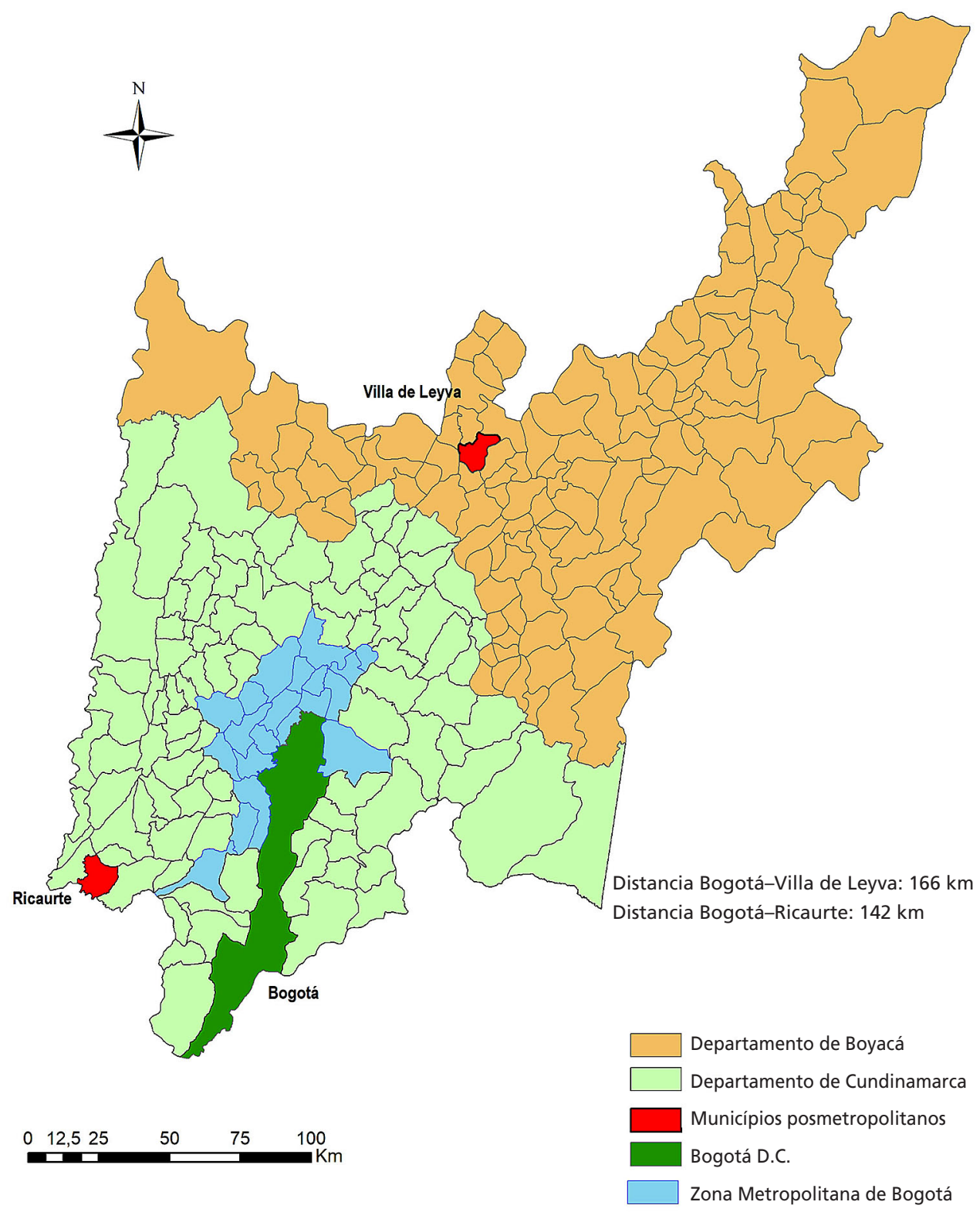

Fuente: Elaboración propia. 
Figura 3 - Licencias expedidas para viviendas nuevas en Ricaurte

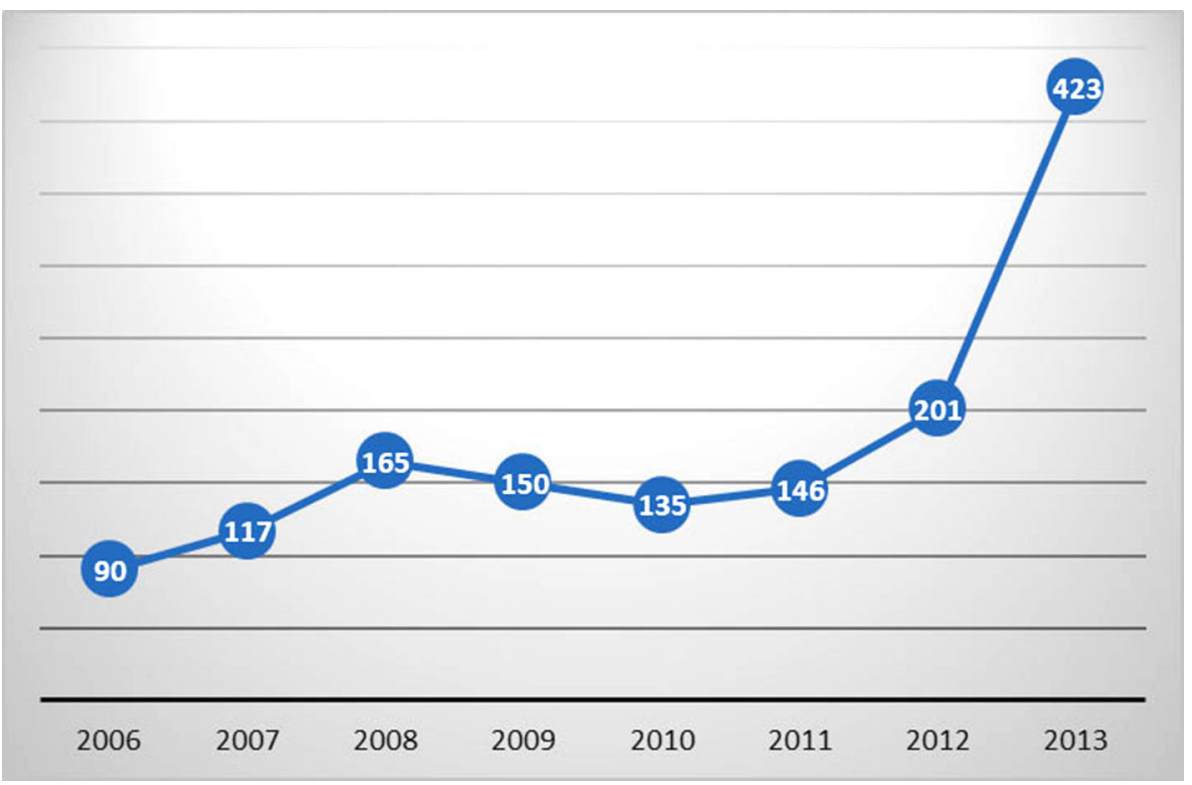

Fuente: Elaboración propia con base en datos de la Secretaría de Planeación municipal, Registro licencias de construcción 2013.

Figura 4 - Licencias expedidas para viviendas nuevas, Villa de Leyva

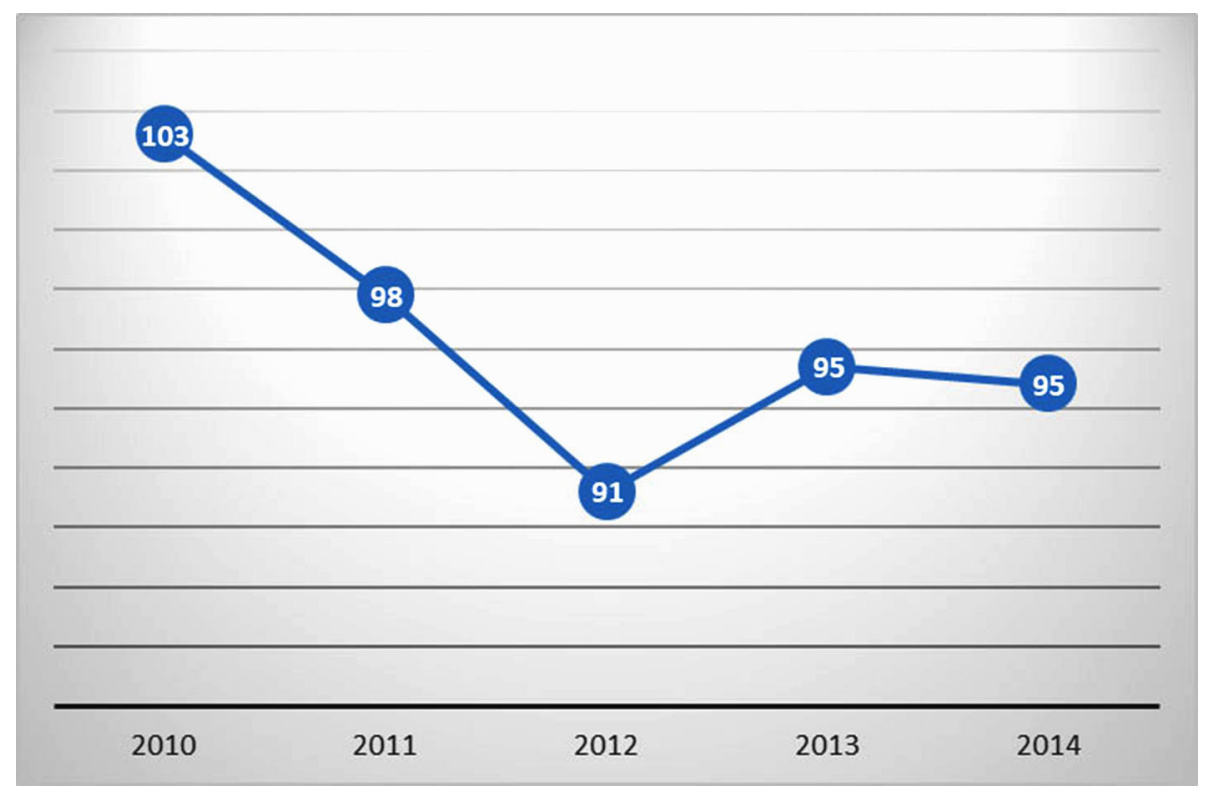

Fuente: Secretaría de Planeación municipal de Villa de Leyva, Registro licencias de construcción. 


\section{Ventajas paisajísticas, ventajas de los climas ecuatoriales}

A partir de la información recopilada en el trabajo de campo se obtuvo un diagnóstico de cada municipio. El primer elemento a destacar es el perfil de los encuestados en Ricaurte, cuyas edades oscilan entre 45 y 70 años. Sumado a ello, todos los encuestados afirman tener un nivel de educación universitaria, lo cual está directamente relacionado con el tipo ocupación u oficio que desarrollan en la actualidad. Aquí es importante señalar que se evidenció una ligera tendencia a la realización de oficios relacionados con la construcción, como es el caso de ingenieros civiles o arquitectos. Igualmente, se observó que el $77 \%$ de los encuestados afirman vivir en un municipio distinto a Ricaurte, siendo Bogotá el lugar de predominio. Se trata de residentes en Bogotá pertenecientes en un $84 \%$ a los estratos 4, 5 y 6. En ese sentido, es Bogotá el lugar donde la mayoría de los encuestados afirman realizar su actividad económica principal.

Por otro lado, al interrogar por los motivos que llevaron a los encuestados a adquirir una vivienda en el municipio de Ricaurte, 54\% de estos hicieron alusión al desear tener un lugar de clima cálido cercano a Bogotá donde tuvieran la posibilidad de descansar en sus tiempos libres. Adicionalmente, motivaciones como el precio de las viviendas o el ver una oportunidad de ingresos en el alquiler de las propiedades, también fueron frecuentes en las repuestas de los encuestados. Igualmente, aunque en menor medida, también se registró que fueron motivaciones familiares (estar cerca de los padres, jubilaciones, etc.) las que llevaron a los encuestados a la compra de la vivienda en el municipio.

En cuanto a las características físicas de las viviendas, se observó que estás cuentan con un mínimo de 2 baños, 3 habitaciones y un parqueadero, aunque se registraron viviendas que superaban este número de baños y habitaciones. De la misma forma, estás viviendas cuentan con la totalidad de servicios públicos, privados o comunales, a excepción del servicio del Gas Natural, que en el $100 \%$ de los encuestados afirmó no poseer este servicio público.

Asimismo, al ser interrogados sobre las características del entorno, más específicamente por la infraestructura tanto del condominio como del municipio, se observó que este tipo de viviendas cuenta con una completa dotación que incluye desde piscinas hasta seguridad privada, pasando por cancha de golf, cancha de tenis y gimnasio. En la misma línea, la totalidad de los encuestados afirman que la dotación urbana con la que cuenta el municipio o los municipios vecinos (Girardot y Melgar) les permite acceder a hospital o centro de salud, iglesia, supermercado, banco o cajero, entre otras, mostrándose muy conformes por ello.

En lo que se refiere a la accesibilidad del municipio, todos los encuestados afirmaron estar satisfechos con las vías de acceso tanto al municipio como a los condominios. Igualmente, también se mostraron conformes con la accesibilidad en carro y en transporte intermunicipal, no obstante, algunos se mostraron un poco inconformes con la accesibilidad en bicicleta, argumentado las largas distancias entre los condominios y el 
municipio, así como también por la falta de vías para realizar estos desplazamientos de forma segura. Sin embargo, todos los encuestados afirmaron estar conformes con la ubicación del proyecto y con la seguridad del municipio.

En cuanto a otros aspectos, se pueden resaltar los siguientes: se percibe un considerable aumento del flujo de personas provenientes de Bogotá en el municipio durante los fines de semana, lo que hace pensar que el municipio de Ricaurte aún posee un marcado carácter turístico y de negocios, además, del atractivo residencial por parte de los habitantes de Bogotá o de otros municipios cercanos. Existe, además, un aumento del flujo de vehículos particulares provenientes de Bogotá en las vías del municipio durante el fin de semana. Este aumento del flujo vehicular también se evidencia en el corredor vehicular entre Ricaurte y los municipios vecinos (Girardot y Melgar), impactando en la movilidad y congestión del tráfico vehicular del municipio.

Se observó una proliferación de Salas de Ventas de constructoras en el corredor vial entre Ricaurte y Girardot en los últimos años. Como también de proyectos de construcción de torres de apartamentos dentro del municipio de Ricaurte y de proyectos de construcción de condominios de casas alrededor del mismo.

Llama la atención que el $46 \%$ señaló el "buen precio" de los proyectos inmobiliarios como una buena razón para adquirir vivienda en el municipio, lo que estaría indicando el comportamiento del mercado del suelo como otro factor a tener en cuenta para que se presente este fenómeno de auto segregación reforzado por la topopoligamia, que le permite a una persona no estar atada a un lugar sino pertenecer a varios mundos (Beck, 2008, p. 148).

Un primer análisis en Ricaurte, da cuenta de la caracterización de la población, según la cual indica la tendencia a un tipo de población cuyo rango se encuentra en la franja etaria mayor de 50 años, es decir, en una etapa que están finalizando el ciclo productivo de la vida y empieza el retiro y se convierten en pensionados. De los entrevistados, el $84,6 \%$ tiene título universitario y el 38,5\% pertenecen al estrato 5, que se puede tomar como indicador para mirar que la población que está llegando al municipio pertenece a un tipo de personas que pertenece a estratos medios y altos. De ellos, $84 \%$ pertenecen a los estratos 4,5 y 6, cifras que, de inicio dan la idea del tipo de personas que se están trasladando a residir habitantes de clase media, adultos mayores en busca de un lugar más tranquilo para residir, pero con la ventaja de mantener un vínculo por la cercanía con Bogotá.

El factor más valorado se refiere la ubicación del proyecto con un $54 \%$. Por otra parte, los aspectos físicos de la vivienda, tales como el diseño, la cantidad o tamaño de habitaciones, así como los factores subjetivos como el confort, la vista y la ausencia de ruido. Además, de otros aspectos identificados como clima, tranquilidad, precio y cercanía a Bogotá. Además, de acuerdo con el análisis de las cifras de población, el censo de 2005 indicó que el 60,8\% de los residentes en el municipio han nacido fuera del municipio de Ricaurte, lo que indica que el municipio es receptor de población residente en otras zonas del país. Se identificaron como principales factores motivadores para adquirir vivienda en el municipio de Ricaurte: 
la posibilidad de vivir en un lugar para descansar, el clima, tranquilidad, cercanía de Bogotá, facilidad de pago, buen precio y la oportunidad para hacer negocios.

El crecimiento y desarrollo del casco urbano de Ricaurte se está modificado, los procesos de suburbanización que se observan en el extremo superior central y derecho de la Figura 5, muestran desarrollos discontinuos con algunas zonas verdes 0 sin desarrollos inmobiliarios visibles. Las imágenes inferiores dan muestra de las construcciones en proceso que implican desarrollos de infraestructuras viales por una mayor presencia de vehículos y también para conectar los nuevos conjuntos de vivienda al casco urbano principal. Además, como se evidencia en las imágenes superiores se observa una proliferación de piscinas que implican una mayor demanda de agua para el consumo ocioso acorde con la oferta de los productos inmobiliarios ofrecidos en el mercado, además del aumento en el consumo de este servicio básico por mayor presencia de residentes dado el incremento en la densidad de las construcciones $y$, por tanto, del número de residentes nuevos en Ricaurte.

Figura 5 - Transformaciones del perímetro urbano, modificaciones del paisaje y algunas modalidades de ocupación residencial, Ricaurte, 2015

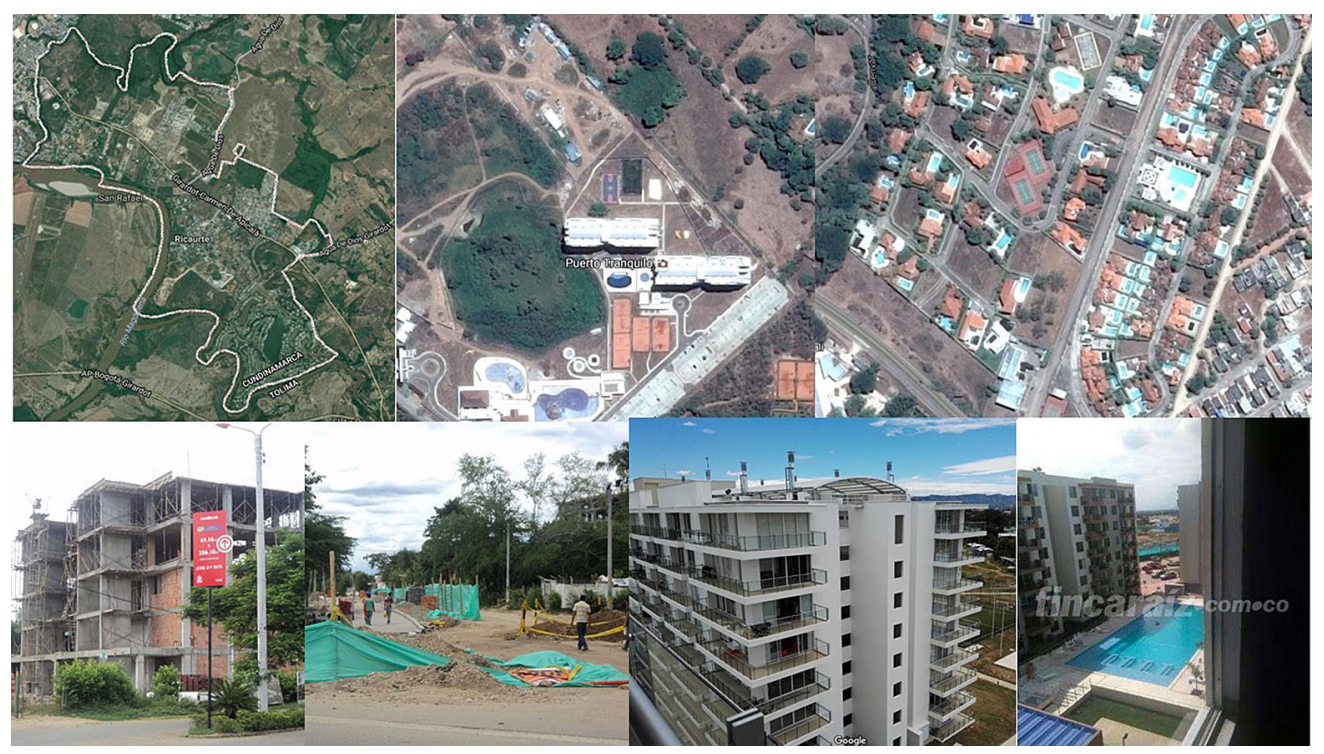

Fuente: https://www.google.com.co/maps/@4.2801103,-74.8092742,12125m/data=!3m1!1e3; www.fincaraiz.com y fotos tomadas por la autora. 
En el extremo opuesto de Ricaurte, al norte de Bogotá, se ubica el otro municipio objeto de análisis, Villa de Leyva en el Departamento de Boyacá. Lamentablemente, la información municipal es bastante precaria y la página oficial del municipio adolece de actualización y no existe información sistematizada sobre licencias de construcción en la Secretaría de Planeación, ni está organizada por estratos. Dentro de las características del entorno que lo hacen atractivo para los residentes y turistas están: la tranquilidad, el paisaje colonial del municipio: la percepción de seguridad, el hecho de contar con buenas vías de acceso desde Bogotá. Además, el atractivo del turismo ecológico y actividades relacionadas con planes de relajamiento.

En Villa de Leyva, se observaron desarrollos inmobiliarios urbanos, que se ubican muy próximos al casco urbano y, en especial, en relación a la proximidad a la Plaza Principal que es el lugar de referencia del municipio, de tal manera, que así los proyectos se ubiquen en algunas veredas están cercanos al caso urbano municipal. Dada esta condición, los proyectos no se ubican a más de $2 \mathrm{~km}$ del área urbana. El $60 \%$ de las licencias de construcción expedidas son para vivienda campestre en la zona suburbana y rural. De ellas el $80 \%$ es para vivienda nueva, lo restante es para ampliación de vivienda urbana, desarrollos en zonas suburbanas y mejoramiento de vivienda. La mayor parte de las licencias expedidas son para estratos 3 y 4 , sin embargo, vale la pena resaltar, que de acuerdo con la información de la Secretaría de Planeación Municipal y los datos recopilados del SUI-Servicio Único de Información de Servicios Públicos Domiciliarios, no existen predios pertenecientes a estrato 6 y la estratificación no corresponde con los estratos que usualmente en Bogotá se catalogan como altos, además, los nuevos proyectos aún no tienen definido el estrato en el cual se clasifiquen.

El $60 \%$ de las construcciones nuevas son para primera residencia y $40 \%$ para extranjeros que vienen a pasar temporadas y, por lo tanto, construyen una casa principal y una casa para los cuidanderos, de tal manera que se asimila a lo que Ulrick Beck, Ilama topopoligamia, cuando habla de personas que para personas que pasan una temporada del año en un lado y otra parte en otro lugar del mundo sin que se sientan ajenos a un lugar u otro. Se sienten igual de identificados en un lugar que en otro. Así, el perfil de los nuevos residentes corresponde a pensionados o adultos mayores en busca de un lugar tranquilo para vivir.

En la Figura 6, se presenta una imagen del casco urbano que se expande con procesos de suburbanización con espacios discontinuos. En la parte inferior izquierda de la imagen se observan el tipo de conjuntos que aprovechan vías rupestres y combinan modalidades inmobiliarias con características de conjunto cerrado, como se observa en la imagen inferior central y a la derecha inferior se observa un conjunto de casas que irrumpen en el paisaje natural andino de Villa de Leyva. 
Figura 6 - Transformaciones del perímetro urbano, modificaciones del paisaje y algunas modalidades de ocupación residencial, Villa de Leyva 2015

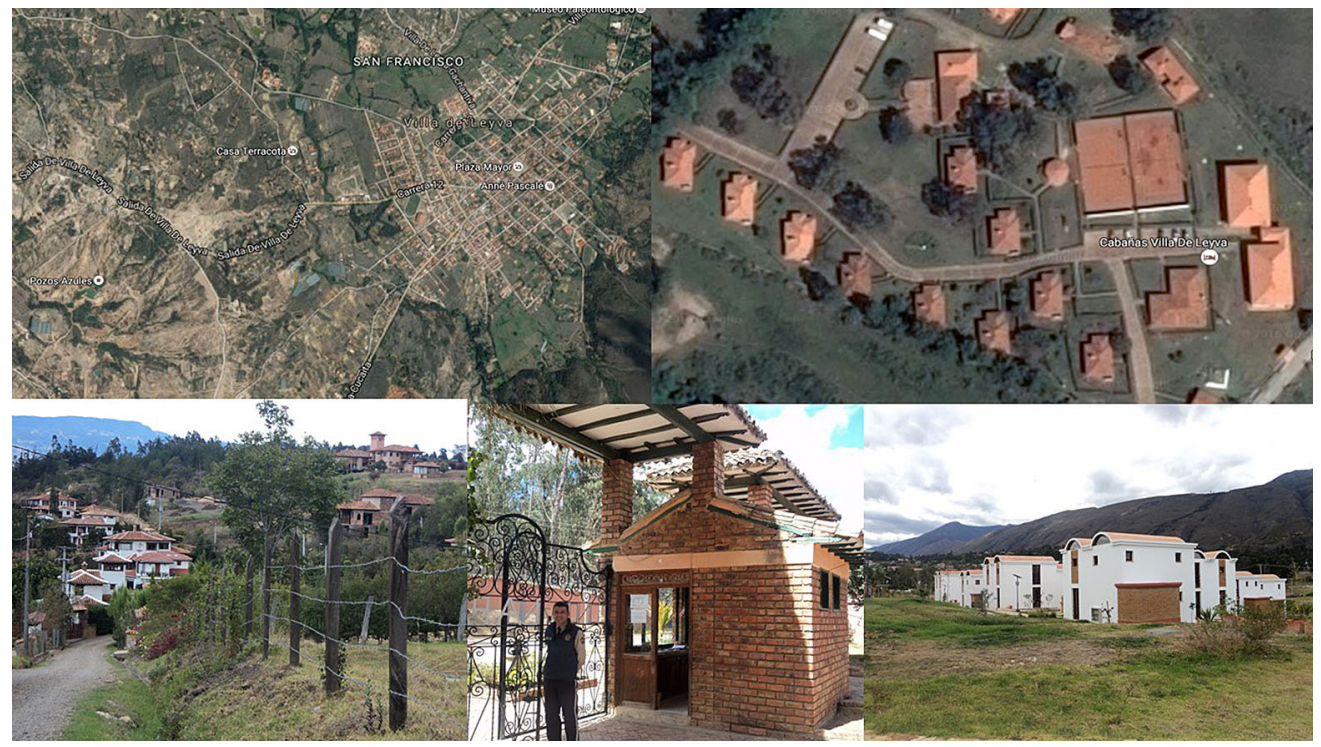

Fuente: https://www.google.com.co/maps/@5.6359718,-73.5294835,3011m/data=!3m1!1e3; imágenes de la autora.

Los recientes desarrollos inmobiliarios encontrados en Villa de Leyva, tienen características que los hacen que estén orientados a clases con estratos económicos altos, aunque se llama la atención sobre el hecho que acorde con la distribución de suscriptores por estrato, la mayor proporción corresponde a los estratos 2 y 3, con $40 \%$ y $42 \%$, respectivamente. No obstante, lo que se debe señalar es que esta clasificación corresponde a la estratificación municipal, es decir, Villa de Leyva, y en general, los municipios aplican la metodología de estratificación y con base en eso clasifican los usuarios, pero esto es parte de la autonomía del municipio y no coincide con lo que, tradicionalmente, se reconoce como estratos 2 y 3 de Bogotá.

Ricaurte se desarrolla como lugar propicio para personas pensionadas, lugar de descanso, sitio para hacer negocios, en contraste con Villa de Leyva, que es un municipio que es escogido por los nuevos habitantes como lugar de retiro para pensionados, pero también un lugar con características pensadas en la población de adultos mayores que van en búsqueda de un lugar para vivir tranquilamente. Es lugar preferido de artistas que buscan un sitio tranquilo en busca de un ambiente propicio para el desarrollo de sus actividades y especialmente, de 
extranjeros que pasan una temporada del año en la ciudad y otra temporada, en sus países de origen. Sin embargo, se constató que hay residentes de origen extranjero que viven permanentemente en Villa de Leyva e inclusive están desarrollando alguna actividad económica, generalmente, de comercio, como bares, restaurantes, etc.

Es de destacar que uno de los proyectos de vivienda visitados en Villa de Leyva, cuenta con un diseño para brindar el bienestar de los adultos mayores residentes en estas viviendas. En este sentido, las viviendas del Conjunto Residencial Villa Teresa cuentan con dos niveles y en el primer piso, se ubica una habitación y, además, el baño tiene la barra de seguridad que generalmente se encuentra en los baños de hospitales o en viviendas que los instalan para que los enfermos o personas de edad se sientan seguras al momento de ducharse. Adicionalmente, los parqueaderos están muy próximos de las entradas de las viviendas teniendo en cuenta las necesidades de desplazamiento para el tipo de población mencionado. Es decir, se trata del desarrollo de un proyecto inmobiliario claramente diferenciado para adultos mayores.

Comparativamente, tanto en Ricaurte como en Villa de Leyva, se verifica la tendencia a la formación de convenciones urbanas (Abramo, 2011), dada la tendencia a localizarse cerca de personas de un perfil socioeconómico similar, definida por la racionalidad mimética y no solamente, la racionalidad paramétrica. En otras palabras, personas que además de mirar su disposición frente al presupuesto que disponen para adquirir la vivienda, además, tienen en cuenta el tipo de personas que son de su misma condición económica.
Se evidencia el fenómeno de la posmetropolización como par dialéctico de la gentrificación, que se observa en Bogotá dados los recientes desarrollos inmobiliarios identificados a partir de la intensificación de la densificación en el centro de la ciudad, en contraposición a la emergencia de la difusión de la población bogotana hacia municipios fuera del área de influencia de Bogotá, analizados como resultado de la revisión de otros fenómenos ligados al estudio de la pos-metropolización. Vale decir, que es esperable que los municipios de Ricaurte y Villa de Leyva se desarrollen y alcancen una dinámica económica, social y tal vez, política que los convierta en un eje que impulse el desarrollo regional.

\section{Consideraciones finales: el posmetropolitanismo como expresión de la fragmentación territorial}

Es necesario replantear las escalas de análisis a los ámbitos metropolitano y pos-metropolitano, además, en los municipios observados se identificaron dos rasgos significativos: la segmentación del mercado y la formación de convenciones urbanas. Al primer rasgo se alude cuando se observa la diferenciación en los productos inmobiliarios, dado que en Ricaurte se identificó la proliferación de oferta de conjuntos conformados por torres de apartamentos, en tanto que en Villa de Leyva se ha privilegiado la construcción de casas en conjuntos cerrados y con estándares altos de construcción al utilizar materiales costosos y de 
primera calidad (maderas importadas, pisos de mármol, entre otros). Por otro lado, la formación de convenciones urbanas se confirma a partir de verificar que las personas buscan vivir cerca de personas de su misma condición económica y en este en particular, cerca de otras personas que son adultos mayores, en edad de jubilarse y que buscan un sitio para descansar.

Es de pensar que se genera una dinámica territorial diferente que implica repensar el ordenamiento territorial al pasar del área de influencia de Bogotá y su "fallida"2 área metropolitana hacia un espacio postmetropolitano. También, se confirma que se impacta la dinámica de los municipios no solo en términos del desarrollo inmobiliario sino en temas tan cruciales como el acceso al agua, ampliación de cobertura de servicios públicos, infraestructura y equipamientos. La escala posmetropolitana resulta una propuesta novedosa e inquietante para el análisis toda vez que introduce una escala territorial que supera los límites de los enfoques que tradicionalmente habían sido observados con anterioridad.

Del análisis hecho, se puede afirmar que los habitantes de Bogotá que se trasladan a estos municipios, lo hacen motivados por la búsqueda de un ambiente más tranquilo y con una dinámica cotidiana menos agitada de la que se vive en Bogotá. Por otro lado, son personas con niveles de ingresos altos, generalmente pensionados y personas independientes con negocios propios, lo que les permite la posibilidad de movilizarse entre un territorio y otro basados en sus deseos y en la búsqueda de la satisfacción personal. En otros términos, en aras de optimizar sus decisiones y maximizar los beneficios recibidos.
Lo que se puede deducir es que estos residentes van en búsqueda de diferenciarse de los demás residentes del municipio, para lo cual, en un primer momento, se autosegregan y, por lo tanto, asumen la decisión de movilizarse de su lugar inicial de vivienda para ocupar los espacios urbanos construidos que hayan seleccionado y que responden a sus requerimientos, sin enfrentarse a restricciones de tipo presupuestal. En estos municipios se observa que "el proceso de reproducción espacial metropolitano que se hace a partir de la articulación entre formas antiguas que sobreviven a la devastación impuesta por lo "nuevo» es marcado por relaciones diferenciadas y por la articulación de tiempos diferenciados" (Carlos, 2007, p. 58).

En este punto de la reflexión, se considera que en línea con el planteamiento de Simmel (2005), la personalidad blasé de los residentes de la ciudad moldeada por el stress urbano estarían determinando los rasgos de los nuevos ocupantes de estos municipios. De igual manera, como señala Alfonso (2015), el orden residencial metropolitano en expansión encuentra en las segmentaciones su rasgo dominante, así como se observa en el comportamiento del mercado inmobiliario de los dos municipios observados donde se ha encontrado que existe un mercado notablemente segmentado para las clases medias y altas que se difunden en el territorio.

Una de las manifestaciones de esta segmentación del mercado se evidencia en la diferenciación en el tipo de bienes inmobiliarios producidos en uno y otro municipio, pues mientras que en Ricaurte las nuevas construcciones corresponden a proyectos de 
torres de edificios con varios pisos de altura, a diferencia de Villa de Leyva cuya oferta principalmente consiste en conjuntos de casas. En 2013, en Ricaurte los proyectos más grandes que se estaban desarrollando era Valkina con 168 apartamentos; Peñalisa Mall que, además, ofrecía hotel, supermercado y centro comercial. También, en ese año empezaba el megaproyecto denominado Puerto Tranquilo (El Tiempo, 2013). Por su parte, Villa de Leyva y como se mencionó anteriormente, al momento de realizar el trabajo de campo, se encontraron por lo menos, seis proyectos nuevos de gran tamaño y con características de altos estándares de calidad y de oferta de bienes y servicios complementarios, como centros comerciales y restaurantes exclusivos como es la publicidad de Santa Fe de la Villa aún en pre venta.

Se destaca aquí el rol de los actores inmobiliarios que ejercen un papel relevante en este proceso, dado que, como ya se señaló antes, al diferenciar los productos ofrecidos generan una segmentación del mercado del cual se apropian y explotan en su propio provecho. Así, a través del trabajo de campo realizado en los dos municipios estudiados se observó que mientras en Ricaurte las firmas constructoras son de trayectoria reconocida en el sector de la construcción, ${ }^{3}$ en tanto que, paradójicamente, en Villa de Leyva, que como se ha anotado está orientado a un tipo de vivienda de alto costo, las firmas constructoras no son reconocidas o, en otros casos, no se daba a conocer el nombre del constructor. Por lo que, Ilama la atención el hecho de que un proyecto de vivienda en Villa de Leyva se hizo su promoción y lanzamiento en Bogotá, lo que da señales para un mercado que, acorde con lo planteado por Haesbaert, "vive al límite" entre uno y otro territorio, y que genera unas relaciones de poder que trascienden desde el ámbito de Bogotá hacia un nivel pos metropolitano con epicentro en Villa de Leyva como lugar para que se asiente una élite social, por decir, más bien para que se auto segregue a partir de las señales que dan los agentes inmobiliarios. Planteamiento que se aproxima a lo que señala Ana Fani Alessandri Carlos, cuando menciona que las ciudades se redefinen por estrategias inmobiliarias que están en función del mercado y que convierten los lugares en una forma de mercancía. (Carlos, 2007, p. 14), de tal manera que, como plantea la autora el espacio urbano se somete a nuevas formas de control no sólo político, territorial sino, además, económico.

De acuerdo con lo observado se puede afirmar que se mantienen los patrones de segregación socio-espacial dado que, los nuevos residentes de los proyectos habitacionales son personas que buscan auto-segregarse y no compartir con clases de menores ingresos, quienes continúan ocupando los lugares disponibles de acuerdo con su nivel socio-económico. No obstante, estos patrones de segregación se dan a gran escala que se verifica en formas de auto-segregación donde las clases con altos ingresos compran la vivienda en localizaciones que otorgan privilegios y exclusividades alejados de los proyectos y programas de viviendas de interés social desarrollados por los gobiernos locales. En municipios como Ricaurte y según palabras del secretario de planeación, no hay espacio para programas de Vivienda de Interés Social (VIS) y en Villa de Leyva solo hay VIS para el sector rural. 
Las ofertas de vivienda para residentes de ingresos medios y altos se caracterizan por conjuntos de vivienda que superan el tamaño de los proyectos ya existentes, porque a modo de ejemplo, en Ricaurte se hizo trabajo de campo en uno de los condominios antiguos y en comparación con los nuevos desarrollos presenta una oferta de bienes adicionales como gimnasios, salones comunales, campos de golf para propiciar nuevos lugares para el desarrollo de los negocios acorde con la vida moderna. Ahora, antes que concluir se debe pensar en el surgimiento de nuevos interrogantes, como mirar si la escala posmetropolitana es la adecuada para pensar sobre los fenómenos que se viven en Bogotá y que reflejan la búsqueda de nuevas formas de apropiar el territorio con miras a buscar soluciones mayores a la gestión urbana y dar el paso a la gestión pos-metropolitana.

En este sentido, en Colombia y, especialmente, en Bogotá y su entorno, se podría pensar que se han dado algunos avances para pensar en la planeación del territorio en un sentido más amplio con el reciente acuerdo para la conformación de la Región Administrativa y de Planificación Especial - Rape, integrada por Bogotá y los departamentos de Cundinamarca, Boyacá, Meta y Tolima a partir de un convenio entre los mandatarios seccionales. Se resalta que los municipios que fueron analizados en este artículo precisamente se encuentran en dos de estos departamentos: Cundinamarca y Boyacá. En este sentido, la Rape se reconoce como un esfuerzo para hacer integración regional y trabajar en el logro de metas conjuntas que permitan un desarrollo regional y un ordenamiento territorial que integre estos entes territoriales, lo que sería un avance para intentar pensar en planificar y tomar decisiones sobre el área de influencia de Bogotá hacia un entorno más amplio: el posmetropolitano.

\section{Melba Rubiano Bríñez}

Universidad Piloto de Colombia, Maestría en Gestión Urbana. Bogotá, Colombia

melbarubiano@gmail.com 


\section{Notas}

(1) El artículo propuesto surge del proyecto de investigación denominado "La difusión espacial de la clase media en ámbitos posmetropolitanos: un estudio de la expansión en la zona metropolitana de Bogotá" realizado en el marco de la línea de investigación Hábitat, Ambiente y Territorio de la Maestría en Gestión Urbana de la Universidad Piloto de Colombia.

(2) A pesar que se acostumbra hablar del área metropolitana de Bogotá, se debe aclarar que esta área no existe sino de hecho porque no ha sido creada legalmente.

(3) Al momento de realizar el trabajo de campo en Ricaurte, se encontraron proyectos en desarrollo por las firmas constructoras Cusezar, Constructora Bolívar y Amarilo.

\section{Referencias}

ABRAMO, P. (2011). La ciudad caleidoscópica - coordinacion espacial y convención urbana - una perspectiva heterodoxa para la economia urbana. Bogota, Universidad Externado de Colombia.

ALCALDÍA MAYOR DE BOGOTÁ (2010). Diagnóstico de la Región Capital Bogotá - Cundinamarca para la revisión del POT de Bogotá.

ALFONSO, O. (ed.) (2001). Ciudad y Región en Colombia: nueve ensayos de análisis socioeconómico y espacial. Bogotá, Colombia, Universidad Externado de Colombia.

(2009). Profundización de las relaciones de metropolización de Bogotá con la Sabana. Ponencia presentada al VIII Seminario ACIUR. Bogotá, Universidad Nacional de Colombia.

(2010). Impactos socioeconómicos y demográficos de la metropolización de la población colombiana y de los mercados de trabajo y residenciales. Documentos de Trabajo Facultad de Economía, 31. Bogotá, Universidad Externado de Colombia.

(2012). El sistema de ciudades y el polimetropolitanismo en Colombia. Revista Questiones Urbanas. Quito/Ecuador, Instituto de la Ciudad, v. 1, n. 1.

(2015). Observatorio Metromun: Índice Alternativo de Desarrollo Municipal 2013 - un estudio a partir de las fragilidades y resistencias del territorio colombiano. Documentos de Trabajo n. 51. Bogotá, Universidad Externado de Colombia.

AUGÉ, M. (2007). Por una antropología de la movilidad. Barcelona/España, Gedisa.

ASCHER, F. (2010). Os novos principios do urbanismo. São Paulo, Romano Guerra.

BECK, U. (2008). ¿Qué es la globalización? Falacias del globalismo respuestas a la globalización. Barcelona, Paidós.

CARLOS, A. F. A. (2007). O espaço urbano: novos escritos sobre a cidade. São Paulo, USP-FFLCH.

EL TIEMPO (2013). Disponible en: http://www.eltiempo.com/archivo/documento/CMS-12735917. Accesso en: 11 abril 2013 
HAESBAERT, R. (2014). Viver no limite: território e multi/transterritorialidade em tempos de insegurança e contenção. Rio de Janeiro, Bernard Brasil.

HATAYA, N.; ALFONSO, O.; CAICEDO, C. e CUERVO, L. M. (1994). Barrio a barrio se construye una ciudad. Descentralización y servicios urbanos en Bogotá. Documentos Ocasionales n. 70. Bogotá, CINEP.

HOSPITAL SAN FRANCISCO DE VILLA DE LEYVA.(2013). Análisis de situación de salud con el modelo de los determinantes sociales de salud. Villa de Leyva, Boyacá.

PEÑA-BARRERA (2010). Índice de Urbanización Municipal: una aplicación a Bogotá y su teórica "Área Metropolitana". Territorios 23, pp. 33-57.

PÉREZ-CAMPUZANO, E. (2011). Segregación socioespacial urbana. Debates contemporáneos e implicaciones para las ciudades mexicanas. Estudios Demográficos y Urbanos, v. 26, n. 2, pp. 403-432. El Colegio de México, A. C., Distrito Federal, México. Disponible en: http://www. redalyc.org/articulo.oa?id=31223581006. Fecha de acceso: 19 out 2015.

RENTERÍA, P. y UMAÑA, M. (2011). Construcción de escenarios para la planificación de la ciudadregión. El Caso Bogotá-Cundinamarca. Cuadernos de Investigación Urbanística, n. 37, pp. 59-66.

REVISTA SEMANA (2010). Región Capital: Bogotá y Cundinamarca son el país entero de una región.

RODRIGUES DE OLIVEIRA JR., H. (2008). Reflexões sobre o estudo da proliferação de condomínios fechados: críticas e sugestões. Cadernos Metrópole. São Paulo, n. 20, pp. 221-239.

RUIZ, C. (2015). Metropolización de las grandes ciudades en Colombia: una aproximación desde las instituciones subnacionales y el desarrollo económico. Tesis de Doctorado. Bogotá D.C., Colombia, Universidad Nacional de Colombia.

SIMMEL, G. (2005). La metrópolis y la vida mental. Bifurcaciones: revista de estudios culturales urbanos, v. 4, n. 7. Universidad Católica del Maule, Chile.

SOJA, E. (2008). Postmetropolis. Estudios críticos sobre las ciudades y las regiones. Madrid, Traficantes de sueños.

SUI - SERVICIO ÚNICO DE INFORMACIÓN DE SERVICIOS PÚBLICOS DOMICILIARIOS. Disponible en: www.sui.gov.co.

Texto recebido em 22/ago/2016

Texto aprovado em 22/set/2016 